\title{
BLOOD TRANSFUSION IN INFANTS BY MEANS OF GLASS TUBES *
}

\author{
BE'TH VINCENT, M.D. \\ BOSTON
}

The value of transfusion in infants has been demonstrated in the treatment of hemorrhagic disease of the new-born and in cases of hemorrhage after injuries or operations. That this procedure has not been more frequently and successfully tried in these conditions is probably due to the technical difficulties of the operation in infants, and especially in the new-born infant. The chief difficulty is found in uniting the artery of the donor to the small and inaccessible vein of the infant. The largest superficial veins of a baby's arm are so small that one must resort to the less accessible veins of the thigh which, at the best, are scarcely large enough. However, when once a satisfactory connection is made between artery and vein, a flow of comparatively short duration is sufficient to transfer enough blood for an infant. In a baby weighing 8 pounds, a flow of five minutes corresponds to thirty or forty minutes in an adult.

The ordinary methods of transfusion are adapted to the requirements of adults and cannot be so successfully applied to infants. Babies have been transfused by the method of direct suture and with the Crile and Elsberg cannula, by men experienced in this kind of work. Less skilful operators using these methods sometimes find it impossible to transfuse a small infant. The unsuccessful attempts result from a failure to start the flow of blood rather than an inability to maintain it for a sufficient length of time.

Under these circumstances it seems more practical to use a method on infants which will lessen the mechanical difficulties of connecting the vessels, even if, in a technical sense, it is not so perfect as the ordinary methods in present use.

It occurred to me that the use of coated glass tubes, as suggested by Brewer in 1909, might simplify this problem. With this end in view, I conducted a series of laboratory experiments to determine how this method might be modified to suit the needs of infants.

The results, and not the details, of these experiments will be given in this paper. I wish more particularly to describe in detail the prep-

*From the Laboratory of Surgical Research, Harvard University Medical School. Read at the fourteenth meeting of the New England Pediatric Society, Boston, Feb. 25, 1911. 
aration and use of these tubes in transfusing infants, and to report three cases which will illustrate their practical application.

Some of the experiments were made on dogs, but most of the work was done with cats, because their small and delicate vessels more nearly resemble those of the infant.

\section{EXPERIMENTAL WORK}

The usual experiment consisted in first bleeding an animal and then reviving it by transfusion, using glass tubes in various lengths and sizes. The common carotid artery of the donor was joined to the recipient's external jugular vein, or one of its smaller branches. In some cases the femoral vessels were used.

The tubes were made from glass tubing of the smallest sizes, cut into lengths varying from 3 to $8 \mathrm{~cm}$. The ends of these tubes were pointed, and all sharp edges smoothed away in the flame. About $3 \mathrm{~mm}$. from either end the tubes were encircled by a shallow groove. This carried the ligature, with which the vessel was tied over the end of the tube.

Straight tubes proved to be better than curved tubes. They are easier to handle and the blood does not clot so quickly in them. The tendency of the blood to clot was found to increase as the tubes were lengthened and their diameters diminished, but a flow of at least ten minutes could always be obtained with tubes $8 \mathrm{~cm}$. in length and $3 \mathrm{~mm}$. in diameter.

Various materials for lubricating or coating the tubes were tried, such as liquid petrolatum, vaselin, stearin, and paraffin, as suggested by Brewer. Vaselin gives too soft a covering and stearin alone is too hard and rough. Paraffin, $54^{\circ}$, is easy to handle and gives a fairly firm, although rather uneven coating. A mixture of vaselin, paraffin and stearin in 2-2-1. proportions gave the smoothest, hardest covering. Blood ran longer without clotting in tubes coated with this mixture than in those coated with paraffin alone. Of any one material, paraffin was by far the most satisfactory. In the course of the experiments, it was found that blood ran surprisingly well in plain glass tubes, and $I$ am sure that they could be used with a fair chance of success if the coated tubes were not available.

The practice gained in working out the technical details in the laboratory was of great value in performing the actual operation on infants.

\section{TECHNIC}

The instruments required in the operation are those of an ordinary dissecting layout, to which are added fine scissors, two pairs of small forceps, at least three mosquito hemostats, and the three small tenacula which come with the Elsberg transfusion cannula. 
These fine hooks are indispensable in exposing the lumen of the vein until it has been dilated and the tube inserted. Crile clamps can be used to control temporarily the donor's artery, but a small, light artery clip is needed for the infant's vein.

The tubes can be freshly prepared in a few minutes before each operation. The mixture of vaselin, paraffin and stearin, which looks like wax and might be conveniently so designated, is kept in a glass dish, or better a metal box. I use a shallow box 5 inches long and 2 inches wide. Its cover, when turned up, serves as a handle.

$I t$ is well to prepare one or two extra tubes for ech transfusion. The dry tubes are placed in the box with the mixture, and sterilized by heating over any convenient flame. The tubes fill by capillary attraction as they sink into the melted wax. One is then taken from the box with a sterile. hemostat which grasps it near the middle. By slowly tipping the tube the wax is made to run from end to end until it covers every surface. The excess is then drawn off by touching the end of the tube with sterile cotton or gauze, which quickly absorbs the melted wax. I have found this easier and more certain than the method of shaking the wax out of the tube. The wax adhering to the tube hardens in a few seconds into a smooth, firm coating which is not damaged by careful handling during the operation. Tubes not perfectly coated are dropped back into the box, reheated and treated as before.

In many of the laboratory experiments, the small amount of air which a tube contains was forced into the recipient's circulation ahead of the donor's blood. Although no evil effects were noted, it is safer to eliminate all danger of air embolism by filling the tubes with salt solution. This can be done with a small glass or soft rubber syringe. A convenient substitute for the syringe is a piece of cotton or gauze saturated with salt solution. The salt solution can be squeezed from this into the tube and held there by placing in one end a plug of sterile cotton covered with vaselin. This plug is removed after the tube has been tied into the infant's vein and just before it is connected with the donor's artery.

About 2 inches of the donor's radial artery is isolated in the usual manner under cocain. The infant is lightly anesthetized and the femoral, the popliteal, or the long saphenous vein is exposed in the thigh. In the cases here reported, the saphenous vein was not readily found, and the dissection was at once carried down to the femoral vein. This vein is of fair size but rather awkwardly placed on account of its depth. If possible, at least an inch of the vein should be freed. It is then clamped above and tied below. The ligature is left long to act as a guide. The vein is partly cut through just above the ligature and two of the small tenacula are hooked into the edges of the cross slit. The vessel is then completely divided and the third hook so placed as to expose its lumen. 
It is important to keep control of the vessel with the hooks in this way, for the lumen is very hard to find if such a delicate vein is allowed to collapse.

The vein is gently dilated with a small hemostat. An infant's vein is fortunately much tougher than a cat's, and a very small vessel can be dilated to a useful size. After washing out the vein with salt solution, the tube, lubricated with vaselin, is inserted and secured with a fine sills ligature.

The donor's artery is clamped, divided and tied over the other end of the tube. One should make certain that the vein is not twisted before the tube is tied into the artery. When the clamp on the artery is removed, the stream of blood is seen to start through the glass tube, but its continued flow can only be verified by the pulsations in the vein and the appearance of the child. An infant is very quickly filled with blood from an adult's radial, and careful watch should be kept of the baby's face to see that the blood is not transfused too rapidly or in too great an amount. In the second case here reported, the child's face became a little dusky at the end of five minutes but regained a normal, red color a few minutes after the transfusion was finished.

\section{CASE REPORTS}

CAse 1.-The first case, one of hemorrhage after a minor operation, was transfused by this method before the laboratory experiments had been completed. William L., an infant aged 6 months, weighing 11 pounds, entered the Boston Floating Hospital July 10, 1910, on account of intestinal indigestion. The next day an indurated mass was noticed in the child's right cheek. During the following twenty-four hours the induration increased and an ulcerated area appeared on the buccal surface of the cheek. July 13, an incision was made into the cheek but no pus was found. After the operation, there was a small but persistent hemorrhage from the wound which continued throughout the night. Several dressings were soaked with blood. In the morning the bleeding not having checked, the child was sent to the Boston Children's Hospital. As far as could be learned, the baby had never bled in this way before, nor was there any suggestion of hemophilia in the family history.

When examined in the Children's Hospital, the child was still losing a little thin, watery blood from a.2-inch incision in the right cheek. The wound was sutured and the oozing stopped. The infant, however, was in poor condition. The skin, lips, and fingers were blanched. The respirations were rapid and shallow, and the pulse, though perceptible, could not be counted at the wrist. The hands and feet were cold. The child was semi-conscious. Preparations were at once made for transfusion. Unfortunately, in the hurry, the hemoglobin and coagulation time were not determined.

The mother, a small woman, served as donor. Her right radial artery was exposed under cocain. The vessel proved to be unusually small. It scarcely seemed half the normal size. The child required little ether. An incision was made over the long saphenous vein at about the middle of the right thigh. The superficial vein not being found after a short search, the dissection was carried down to the femoral vein above Hunter's canal. The vessel was isolated for about an inch of its length and connected with the donor's artery by means of a coated glass tube, in the manner already described. In this case the tube was not filled with salt solution, but the air which passed into the infant's circulation 
apparently did no harm. The tube was $6 \mathrm{~cm}$. in length and $2.5 \mathrm{~mm}$. in diameter. The flow of blood lasted for about seven minutes. When disconnected at the end of ten minutes, the tube was filled with a clot. In that time the child's color had greatly improved. Lips, ears and fingers showed a red tinge. The breathing was slower and deeper and the pulse stronger and fuller at the wrist. After ligating the femoral vein the lower leg became swollen and slightly blue. This passed away in a few hours. One hour after the operation, the child's pulse had fallen to 140 . The improved condition, which immediately followed the operation, was maintained during the day and succeeding night. From this point the convalescence was uneventful and the infant was referred back to the Floating Hospital ten days after the transfusion.

Case 2.-The second case was one of hemorrhagic disease of the new-born. James S., was referred to the Infant's Hospital in Boston by Dr. Homan of Everett, Mass., Oct. 11, 1910. The child, born two days before, at full term, normal delivery, was perfectly well up to $1 \mathrm{a} . \mathrm{m}$. on the day of entrance, when he began to vomit blood in large elots. He vomited frequently and spat up bright, red blood after each feeding. During the day he had three movements containing red blood. He was brought to the hospital at $4 \mathrm{p} . \mathrm{m}$.

The child weighed $61 / 2$ pounds. The skin was slightly jaundiced and very pale. There was still a trace of color in the lips. About the mouth and anus, the skin was stained with fresh blood. There were several small points of subcutaneous hemorrhages on the upper lip and in the groin. Heart, lungs and abdomen were negative. The umbilical cord was normal. The pulse could be felt at the wrist, but was too rapid to count accurately.

The infant had evidently lost considerable blood, enough to seriously affect his condition, and was in a poor state to resist any further hemorrhage. For this reason it seemed best not to temporize with the less radical measures, but to proceed, as soon as possible, with a transfusion which would stop the bleeding and, at the same time, restore the celiular elements of the blood. The father of the child served as donor. While awaiting his arrival, and preparing for the operation, the infant vomited blood twice and passed another bloody stool.

The father's left radial artery was exposed under cocain in the usual manner. The child was then given a little ether and its femoral vein isolated for about one inch in the middle of the thigh. The vein was collapsed, and, in this state, seemed scarcely more than one millimeter in diameter. Considerable difficulty was experienced in exposing the lumen of such a small vein, but once the three hooks were in place, it was possible to dilate it enough to admit the tube. Following the technic already described, the vessels of the donor and recipient were connected with a coated glass tube $8 \mathrm{~cm}$. long and $3 \mathrm{~mm}$. in diameter. In this case the entrance of air was obviated by using a tube filled with salt solution. The blood had been flowing for about one minute when, by some mischance, the tube was pulled from the father's artery. Before it could be replaced, the blood had clotted in its lumen. The extra tube which had been prepared was then substituted and the blood allowed to flow for four minutes. The infant rapidly took on a healthy, red color. The face was becoming a trifle dusky when the transfusion was brought to an end. Counting the time the first tube was in use, the total flow must have been of about five minutes' duration.

The next day the patient was to all appearances a normal, healthy baby. There was no more bleeding. He vomited once after the first whey feeding. During the day he passed two dark movements. Three days after the transfusion the wound was clean and the infant was sent home to be nursed by the mother. A month later he was reported in perfect health.

CASE 3.-The third case was referred to the Infant's Hospital for hemorrhagic disease of the new-born Feb. 18, 1911. Chester P. was born four days before entrance, and for the first two days appeared to be a normal, healthy baby. On the third day he did not seem so well and passed a movement containing dark blood. The next day the baby had six black movements consisting, for the most 
part, of elotted blood. He vomited once but the vomitus contained no blood. The bleeding from the bowel continued until the infant became too weak to nurse, and he had lost his healthy color when brought to the hospital at $1: 30$ p. m. on the fifth day.

When examined at $4 \mathrm{p} . \mathrm{m}$. he was pale but not blanched. There was some color in the lips and fingers. He had a strong cry. Heart and lungs were negative. An odor from the umbilical dressing could be easily detected. The cord was moist and sloughing, but there was no redness or induration in the slsin about the umbilicus. The temperature was subnormal. The pulse was 150 at the wrist, and the respirations were regular and not rapid. The hemoglobin was 35 per cent.

At 5 p. $\mathrm{m}$. the baby had a large, dark movement with a suggestion of red color. At $6 \mathrm{p}$. $\mathrm{m}$. there was another dark movement but no fresh blood. At 9 p. m. he had a small, dark movement with a little fresh blood.

The baby was given 10 c.c. of a thrombin solution, prepared by Dr. W. P. Lucas, at 11 p. m., and this was repeated twice the next morning. During the night the infant had a normal fecal movement but at $8 \mathrm{a} . \mathrm{m}$. he passed another dark stool containing a little fresh blood. 'The morning temperature was $101.8 \mathrm{~F}$.

At this time the baby's condition seemed as good or better than the day before, and it was decided to postpone transfusion, with the understanding that it should be done in the evening for any more bleeding, even if the infant's condition had not become worse.

The baby showed no change up to $1: 30 \mathrm{p} . \mathrm{m}$. when there was a sudden collapse. He lost all his color, the breathing became labored and the pulse was imperceptible at the wrist; hands and feet were cold. He passed a small movement of fresh blood. The father was summoned at once to serve as donor.

The operation began at $2: 30 \mathrm{p} . \mathrm{m}$. The father's left radial artery was exposed under cocain. The baby needed almost no ether. His femoral vein was isolated in the left thigh. The subcutaneous tissues were exsanguinated and the little blood which escaped from the deeper vessels was thin and watery. The coated tube used in this case was $12 \mathrm{~cm}$. long and $3 \mathrm{~mm}$. in diameter and this extra. length made it easier to complete the connection with the donor's artery.

The father had a strong pulse and large radial, and the baby was filled with blood very rapidly. The connection was maintained for four minutes, and during this period the flow was checked three times, for a few seconds, when the infant's face became a little dusky. At the end of the operation the child began to struggle and cry vigorously. The hemoglobin, taken immediately after the transfusion, was 90 per cent.

The baby slept well during the night. He regurgitated his feeding once and had one dark movement. There was no sign of fresh bleeding. In the morning the temperature was $99.8 \mathrm{~F}$. During the day he had two more dark movements. The second day after the operation the temperature was normal and the baby passed a normal, yellow movement. One week after the transfusion, the infant was taking his feedings well. He had a good color and normal temperature.

295 Beacon Street. 